DESIGN OF WASTE VEGETABLE OIL COLLECTION NETWORKS APPLYING VEHICLE ROUTING PROBLEM AND SIMULTANEOUS PICKUP AND DELIVERY

Lisandra Quintana; Yalexa Herrera-Mena; José L. Martínez-Flores; Marcos A. Coronado; Gisela Montero; Patricia Cano-Olivos

\title{
DESIGN OF WASTE VEGETABLE OIL COLLECTION NETWORKS APPLYING VEHICLE ROUTING PROBLEM AND SIMULTANEOUS PICKUP AND DELIVERY
}

\author{
Lisandra Quintana \\ Universidad Autónoma de Baja California, Instituto de Ingeniería, Calle de la Normal y Blvd. Benito Juárez S/N, \\ 21280, Mexicali, B.C, Mexico, quintana.lisandra@uabc.edu.mx \\ Yalexa Herrera-Mena \\ Universidad Popular Autónoma del Estado de Puebla, Calle 17 Sur 711, 72410, Puebla, Mexico, \\ yalexa.herrera@upaep.edu.mx \\ José L. Martínez-Flores \\ Universidad Popular Autónoma del Estado de Puebla, Calle 17 Sur 711, 72410, Puebla, Mexico, \\ joseluis.martinez01@upaep.mx \\ Marcos A. Coronado \\ Universidad Autónoma de Baja California, Instituto de Ingeniería, Calle de la Normal y Blvd. Benito Juárez S/N, \\ 21280, Mexicali, B.C, Mexico, marcos.coronado@uabc.edu.mx (corresponding author)

\section{Gisela Montero} \\ Universidad Autónoma de Baja California, Instituto de Ingeniería, Calle de la Normal y Blvd. Benito Juárez S/N, \\ 21280, Mexicali, B.C, Mexico, gmontero@uabc.edu.mx \\ Patricia Cano-Olivos \\ Universidad Popular Autónoma del Estado de Puebla, Calle 17 Sur 711, 72410, Puebla, Mexico, \\ patricia.cano@upaep.mx
}

Keywords: Vehicle Routing Problem Simultaneous Pickup and Delivery - VRPSPD, waste vegetable oil, recovery logistics

Abstract: The growth of industrialization in Mexico has caused an increase in the demand for materials to satisfy the consumption of goods and services of a growing population. Given this scenario, there is a rise of the residual generation with affectations on the ecosystem and population health. Hence, the objective of this research was to design a network for waste vegetable oil collection based on vehicle routing problem with simultaneous pickup and delivery, starting from a distribution centre to 49 restaurants, as the generation sources of waste vegetable oil. The Vehicle Routing Problem Simultaneous Pickup and Delivery with Time Windows was the variant used as a vehicle routing method to solve the problem. The free software VPRPD was the tool used to solve the vehicle routing problem with simultaneous pickup and delivery that allowed to specify time restrictions. This software uses the simulated annealing metaheuristics in its syntax. As a result, it was obtained a total of 8 networks, for a vehicle capacity utilization of 70 percent in the $6 t$ vehicle and 46 percent in the $8 t$ vehicle.

\section{Introduction}

The growth for industrialization in Mexico has caused an increase in the demand of materials to satisfy the consumption of goods and services of a growing population. Given this scenario, the increase in residual generation at the national level is evident, with affectations on the ecosystem and population health. Therefore, it is everyone's responsibility to find solutions that help mitigate these damages [1]. Scientific and technical advances have made it possible to identify that many of these wastes can be a potential feedstock in several production processes [2-5].

An example of this waste generation is the vegetable oil supply chain, where the last user generates waste vegetable oil (WVO), a residue obtained from frying food. This waste is recovered when it is subjected to a physical treatment process, becoming a good enough material that can be used in the production systems of the chemical industry for the production of biofuel as well as a food supplement for the livestock sector. The commercial value of the waste vegetable oil is evident, therefore, it is necessary to design logistic networks that transport the residual from the generation sources to a collection centre, where it can be treated and valorised. It would not only have a positive environmental and social impact; it would also open up new business opportunities with sustainable competitive advantages.

Residual management and products recovery are a complex problem that requires planning, management and, control of the flow of materials and products [6]. Hence, the recovery logistics process has a fundamental role, 
DESIGN OF WASTE VEGETABLE OIL COLLECTION NETWORKS APPLYING VEHICLE ROUTING PROBLEM AND SIMULTANEOUS PICKUP AND DELIVERY

Lisandra Quintana; Yalexa Herrera-Mena; José L. Martínez-Flores; Marcos A. Coronado; Gisela Montero; Patricia Cano-Olivos

which requires the design, development, and control of a system to collect the out-of-use product, and logistics management must be supported by strategic, tactical, and operational decisions [7].

This research is focused on the design of a waste vegetable oil pickup network from a residual recycling company located in the north of Mexico. Nowadays, the recycling company has 151 clients and wishes to expand by incorporating 49 new generation points (restaurants that generate waste vegetable oil). However, the company that outsources the pickup service is at the limit of its capacity and it is not able to incorporate more clients. Therefore, the company must design a collection network to attend the demand of these new clients.

\subsection{Importance of logistics in residual management}

Since 2013, with the General Law for the Prevention and Integral Management of Residual, in Mexico, government actions have been carried out to mitigate the environmental and social damage generated by the indiscriminate dumping of waste into the environment. At the beginning of 2019, the Ministry of the Environment and Natural Resources began the Zero Waste Project, which seeks the modification of the current schedule for a new one following the principles of circular economy model [8].

The circular economy is a system designed to be restored and regenerative [9]. The circular economy is an "alternative growth discourse" and not an "alternative to the growth discourse". It is a model that follows a continuous development cycle, preserves and increases natural capital, optimizes resource returns, and minimizes system risks, managing finite stock and renewable flows [10]. This philosophy assumes that the life cycle of a product ranges from its production to its recovery or reduction after it is used [11].

The adoption of a circular economy program implies that the company has to carry out different strategies focused on improving the circularity of its production system and also cooperates with other supply chains to achieve greater efficiency [12]. It is a direct result of a national political strategy and therefore a top-down approach, and its implementation is structured following both a horizontal and a vertical approach [13].

Despite the fact that in Mexico there are more than 100 laws, regulations, and standards for efficient residual management [14], there is still a weakness in the materialization of programs and plans to increase the reuse, recycling, and reduction of waste. Therefore, it is necessary to know the actual generation volume of each residual, the uses that can be given to them in other production chains, as well as determine the capacity that the logistics system must have for it to have value as a raw material.

Given the need for production systems of the industrial sector to be more sustainable, with cleaner processes and a closed life cycle; it is important to design logistic systems that enable the recovery of material and feedstock with a high added value. It is a challenge since the business sector considers that residual recovery processes are not very profitable. Therefore, the continuous improvement of the logistic processes and fundamentally, the optimization of the collection networks is one of the elements is necessary to work seeking to optimize resources.

\subsection{Vehicle Routing Problem}

One of the fundamental and sensitive elements in the logistics system of reuse is the transport of the residual from the point of generation to the depots of the recovery centre. Currently, there are numerous situations in which it is necessary to manage the transport of products in both directions: customer returns, obsolete products, and seasonal inventories [15], inputs for collection of the waste.

To manage this scenario in an integrated and efficient way, the following elements must be considered:

- The number of clients and their characteristics.

- Location.

- Collection capacity.

- Collection frequency.

- Quantity of a product to be collected.

- Characteristics of the vehicles.

- Human resource.

- Type of product and its characteristics.

- Environmental characteristics.

Carrying out the pickup and delivery of products requires the design of a distribution and recovery system of products in an integrated way, looking forward to the optimization of the vehicle fleet and time. For this reason, mathematical models of vehicle routing problems (VRP) and their variants become tools for finding optimal and feasible solutions. There are two broad categories defined: the homogeneous VRP and the heterogeneous VRP. Homogeneous VRP refers to common characteristics where all nodes handle the same resource such as distance, time windows, returns, and fractional deliveries. Heterogeneous VRP refers to unequal components where each node handles different resources such as vehicle fleet, tanks, trips, and stochastic components in some cases [16].

Homogeneous VRP's are:

- DCVRP. It is a VRP with distance and capacity restrictions, this is the Capacity Restricted Vehicle Routing Problems (CVRP).

- VRPTW. It is a VRP with distance and capacity restrictions, where customers are associated to visit in a certain time-space.

- VRPB. In the VRP with backhauls, consumers can demand or give back some products. Vehicle Routing Problems Pickup and Delivery (VRPPD) is a variant of the VRPB.

- $\quad$ SDVRP. It is a relaxation of the VRP where it allows the same client to be visited by different vehicles as long as the cost is reduced. 
DESIGN OF WASTE VEGETABLE OIL COLLECTION NETWORKS APPLYING VEHICLE ROUTING PROBLEM AND SIMULTANEOUS PICKUP AND DELIVERY

Lisandra Quintana; Yalexa Herrera-Mena; José L. Martínez-Flores; Marcos A. Coronado; Gisela Montero; Patricia Cano-Olivos

Different variants of the VRPPD were developed between 1999 and 2016, in which two situations were considered: a static environment [17], which occurs when all the input data of the problem is known before the construction or design of the routes and the planning horizon is limited, and a dynamic environment [18], where some input data are known or updated during the period in which the delivery and pickup operations of the products takes place. However, most of the delivery and pickup problems have been focused on the static scenario and few authors have worked on the dynamic part of the problem.

The VRP problem with simultaneous deliveries and pickup (VRPSPD) is one of the variants of VRPPD and was first addressed by Hokey Min in 1989 [19], who recognizes that it can exist simultaneously delivered and pickup in the same node. The objective of the VRPSPD is to find a series of routes for a set of vehicles at a minimum cost, in order to serve customers in the most appropriate way, which fulfils the restriction that the vehicles have sufficient transport capacity for the products (or persons) that must be collected and/or delivered and pickup to each customer (node). It must start from a depot and arrive at the same depot. The aim is to find the optimum solution or quality sub-optimal solutions. This is a combinatorial optimization problem and most of its versions are of the NP-Hard class, meaning that the solution cannot be found in polynomial time [20].

Unlike the classic vehicle routing problem, in VRPSPD the feasibility of routes is determined not only by the subset of clients that makes up the route but also, the order in which they are visited. The first condition requires that the total of transported products does not exceed the capacity of the vehicle. The element of order is added because, at all times, the load is a mixture between the product previously collected from the customers visited and those yet to be delivered. Due to the fluctuation in the load, even when the total demand does not exceed the capacity of the vehicles, there may be intermediate points on the route where this does happen [15].

The VRPSPD, like the rest of the problems derived from the VRP, has among its variants the following [21]:

- VRPSPD + heterogeneous fleet, considering capacity, costs, availability, and circulation restrictions as elements of heterogeneity.

- VRPSPD + different maximum route length limitations for each vehicle type, considering the heterogeneous fleet in terms of capacity, cost, and availability.

- VRPSPD + maximum route duration limitation, considering the heterogeneous fleet in terms of capacity, cost, availability, and loading/unloading, and travel speed.

- VRPSPD + soft windows, considering the heterogeneous fleet in terms of capacity, costs, availability, and speed of loading/unloading, and travel.

This last variant is known in the Vehicle Routing Problem Simultaneous Pickup and Delivery with Time Windows (VRPSDPTW) and aims to minimize the difference between routing costs and incomes associated with pickups [20].

VRPSDP is the least studied or applied in the literature and most of the authors consulted assume elements that facilitate the search of a solution, which in some are theoretical solutions that are far away from what happens in real life. Some authors [22] have found optimal solutions using exact methods but have had to make assumptions such unlimited number of vehicles and number of nodes or clients to visit less than 30, this makes it an NP-hard problem.

VRPSPD is one of the least addressed types of VRP in the literature because of its complexity, since the search for optimal solutions can increase exponentially depending on the number of customers or nodes that are part of the problem. Therefore, the computational resources that work with exact algorithms could not be used in scenarios with more than 40 clients. Consequently, the heuristic or metaheuristic algorithms are the most used to find a solution that, even if is not optimal can be feasible.

\section{Methodology}

The objective of this research was to design a waste vegetable oil collection network to attend the demand of 49 generation sources. Based on the VRPSPD, a mathematical model is designed considering the restrictions of the studied network. Finally, a simulated annealing metaheuristic algorithm was used to obtain a feasible solution.

\subsection{Problem Statement}

The company increases its client portfolio each year as the capacity to treat residual raises, as well as the awareness of the production chains to have cleaner, more sustainable, and environmentally friendly processes.

The company specializes in the maintenance and cleaning of grease traps, as well as hoods, adding a service of waste vegetable grease collection, which they use for biodiesel production. The grease collection service is outsourced to a company dedicated to the transportation and distribution of products. Currently, that company cannot assume the commitment to include the 49 generation points that the recycling company wishes to add in its client portfolio. Therefore, the recycling company needs to conduct a study to determine if it has the capacity to execute the collection process for new clients. The locations of existing customers and the new ones to be incorporated are showed in Figure 1. 
DESIGN OF WASTE VEGETABLE OIL COLLECTION NETWORKS APPLYING VEHICLE ROUTING PROBLEM AND SIMULTANEOUS PICKUP AND DELIVERY

Lisandra Quintana; Yalexa Herrera-Mena; José L. Martínez-Flores; Marcos A. Coronado; Gisela Montero; Patricia Cano-Olivos

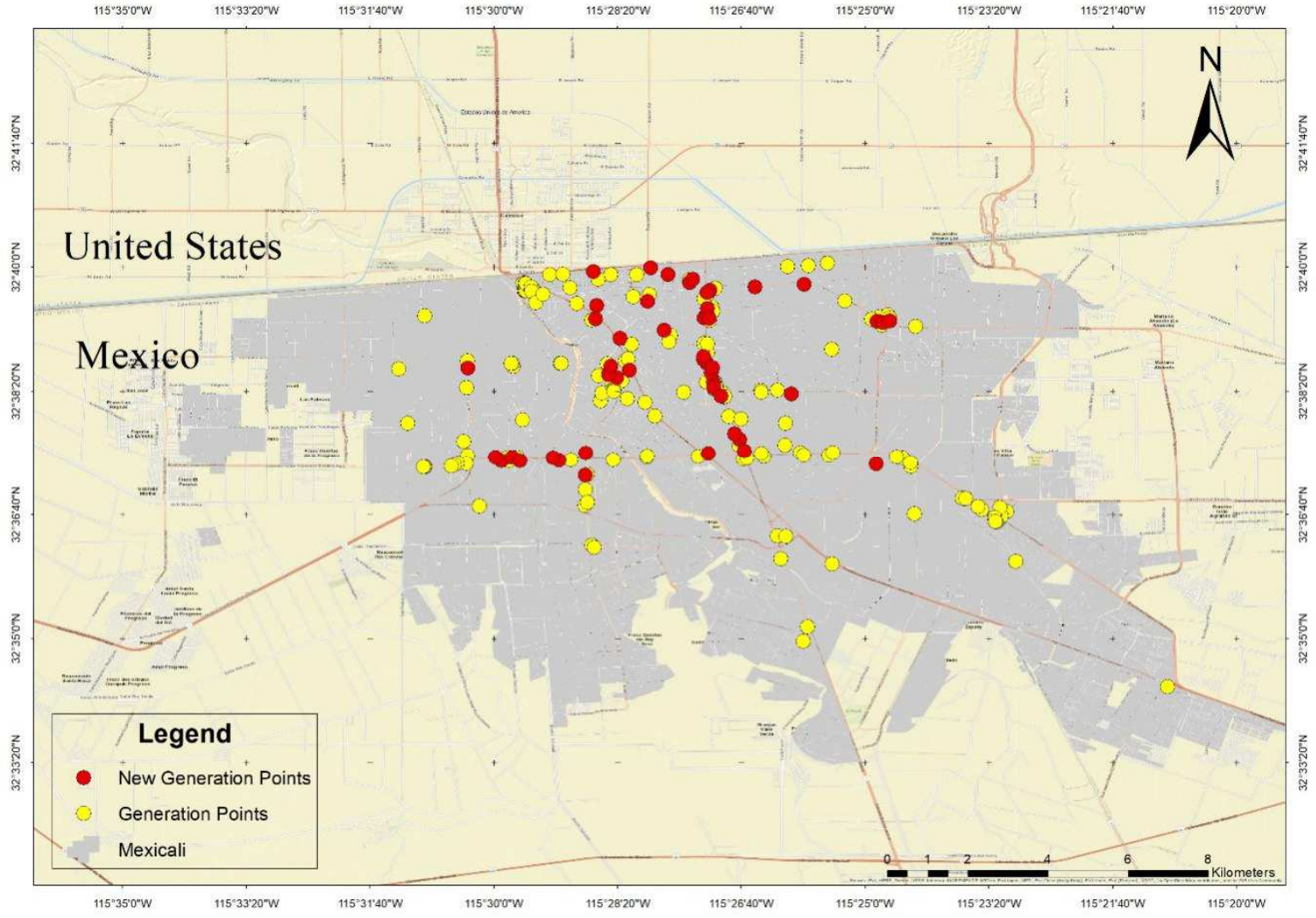

Figure 1 Location of WVO generation points

The objective of the collection process is to deliver empty containers to the points of generation for the collection of residual and to collect containers with WVO. In this process, it is necessary to consider that:

- The generation point will be visited only once; and the opening, closing, and resting times of each point.

- The collection center has two vans, $6 \mathrm{t}$ and $8 \mathrm{t}$ dedicated exclusively to the delivery of empty containers and the collection of full containers at each generation point.

- Deliveries of empty containers and collections of full containers would be made simultaneously.

- 20 L containers will be delivered so that the residual is collected at each generation point.

\subsection{Method of solution}

Knowing the characteristics of the collection process, it is a VRPSPD with elements of a VRPTW, being then a VRPSPDTW. Both models belong to the family of vehicle routing problems with capacity restrictions. Both consider that all routes start and end at the collection centre. At no point of the route can the load exceed the capacity of the vehicle, the vehicles have different capacities and can make at most one trip. For the solution of the problem, it is estimated that the load of the vehicle is a mixture of the products collected from the clients already visited and the one that remains to be visited. Also, it was considered that each establishment has time to attend the vehicle that makes the delivery and collection of the product.

A route is an ordered sequence of customers associated with a specific vehicle. In short, it is a problem where the starting point is a collection centre with a heterogeneous fleet of vehicles and a set of generation points are visited. At each point, there is a demand for $20 \mathrm{~L}$ containers, known as delivery demand and $20 \mathrm{~L}$ containers containing WVO are for pickup, known as the pickup demand. Both, the collection centre and the generation points have time restrictions to attend the delivery and pickup process. Therefore, a network is designed to satisfy the demand of all customers, optimizing the distance and travel time.

\subsubsection{Design of the mathematical model of the Vehicle Routing Problem Simultaneous Pickup and Delivery with Time Windows}

The objective of the VRPSPDTW is to determine the set of routes that satisfies the demand of all the clients by optimizing the distance, fulfil the demand of the clients, and attending to their time restrictions. The parameters and variables that define the model are shown in Table 1. 
DESIGN OF WASTE VEGETABLE OIL COLLECTION NETWORKS APPLYING VEHICLE ROUTING PROBLEM AND SIMULTANEOUS PICKUP AND DELIVERY

Lisandra Quintana; Yalexa Herrera-Mena; José L. Martínez-Flores; Marcos A. Coronado; Gisela Montero; Patricia Cano-Olivos

Table 1 Variables and parameters that define the VRPSPDTW

\begin{tabular}{|c|c|}
\hline Variables & Parameters \\
\hline $\begin{array}{l}x_{i j}^{k} \text { : The arc }(i, j) \text { with } i, j \in I^{+} \text {is traversed by the } \\
\text { vehicle } k \epsilon K \text {. } \\
t_{i j}^{k} \text { : Vehicle travel time } k \in K \text { through the arc }(i, j) \\
\text { with } i, j \in I^{+} \text {. } \\
\qquad t_{i j}^{k}=C_{i j} / v^{k} \\
t_{i}^{k}: \text { Time in the vehicle } k \in K \text { up to the customer } i \\
\epsilon I \text {. } \\
s_{i j}^{k} \text { : Time of service. } \\
\qquad s_{i j}^{k}=\left(d_{i}+p_{i}\right) * h^{k} \\
\text { Dij: Represents the quantity of products to be } \\
\text { delivered transported by the arc }(i, j) i, j \in I^{+} \text {. } \\
\text { Pij: Represents the quantity of products to be } \\
\text { pickup transported by the arc }(i, j) i, j \in I^{+} \text {. } \\
\text { Cij: Variable to optimize in this case the distance } \\
\text { from node } i \text { to } j \text {. }\end{array}$ & $\begin{array}{l}\text { I: Set of clients } I=\{1,2,3 \ldots \ldots n\} I^{+}=I \cup\{0\} \\
\text { di: Quantity of products to be delivered with } i \in \\
\text { I. } \\
p_{i} \text { : Quantity of products to be pickup with } i \in I \text {. } \\
\text { m: Quantity of vehicles. } \\
\text { Q: Number of vehicles. } \\
h^{k} \text { : Loading/unloading speed. } \\
v^{k} \text { : Constant associated with the average speed of } \\
\text { the vehicle. }\end{array}$ \\
\hline
\end{tabular}

The mathematical model presented is based on the models defined by $[20,21,23]$. The problem is modelled on a graph, being the vertices the clients and the deposit, so the set $\mathrm{I}+$ and the arcs are the paths between these vertices.

\section{Objective function:}

Restrictions:

$$
\min \sum_{k=1}^{m} \sum_{i, j \in I^{+}} C i j * x_{i j}^{k}
$$

$$
\begin{array}{rrr}
\sum_{k=1}^{m} \sum_{j \in I^{+}} x_{i j}^{k}=1 & \forall i \in I \\
\sum_{j \in I^{+}} x_{j s}^{k}-\sum_{j \in I^{+}} x_{s j}^{k}=0 & \forall s \in I^{+}, \forall k \in K \\
\sum_{j \in I} x_{0 j}^{k} \leq m^{k} & \forall k \in K \\
\sum_{j \in I} D_{o j}=\sum_{i \in I} d_{i} & \\
\sum_{j \in I} P_{j 0}=\sum_{i \in I} p_{i} & \\
\sum_{j \in I^{+}} D_{j i}-\sum_{j \in I^{+}} D_{i j}=d_{i} & \forall i \in I \\
\sum_{j \in I^{+}} P_{i j}-\sum_{j \in I^{+}} P_{j i}=p_{i} & \forall i \in I \\
P_{i j}+D_{i j} \leq \sum_{k=1}^{m} x_{i j}^{k} Q^{k} & \forall i, j \in I^{+} \\
t_{0}^{k}=0 & \forall k \in K \\
x_{i j}^{k}\left(t_{i}^{k}+s_{i}^{k}+t_{i j}^{k}-t_{j}^{k}\right) \leq 0 & \forall i, j \in I^{+}, \forall k \in K \\
t_{i}^{k} \geq 0 & \forall i \in I, \forall k \in K \\
x_{i j}^{k} \in\{0,1\} & \forall i, j \in I^{+}, \forall k \in K \\
D_{i j} \geq 0 & \forall i, j \in I^{+} \\
P_{i j} \geq 0 & \forall i, j \in I^{+}
\end{array}
$$

The objective function (1) minimizes the travel distance. The restriction (2) ensures that all customers are visited once. The continuity of the distance travelled from one point is guaranteed by the restriction (3). It (4) ensures that each vehicle is used only once and taking into account that the vehicle fleet is heterogeneous. Restrictions (5) and (6) ensure that everything that is collected is taken to the depot and that everything that is to be delivered is in the depot (7) an (8) ensure that the demands of pickup and delivery at each customer are attended. In the case of (9), it indicates that the product can only be distributed through the arch included in the solution. With (10) it is guaranteed that all vehicles leave the warehouse at the initial moment. The relationship between the arrival times of consecutive customers on a route is defined in the restriction (11), (12) makes the arrival time a non-negative value. Finally, (13) is associated with the domain, and (14), (15) are the nonnegative conditions.

\subsubsection{The Vehicle Routing Problem Simultaneous Pickup and Delivery with Time Windows solution}

Previously knowing the amount of data to process and the complexity of the mathematical model of the problem to be solved, a metaheuristic algorithm was used, to get a feasible solution in less time. Using a metaheuristic algorithm prevents the solution from falling into optimum locations as there are intelligent and high- level procedures. The free software VPRPD was used to solve the problem. This software uses the simulated annealing metaheuristics in its syntax. These metaheuristics has an algorithm that selects candidates randomly and allows degraded solutions, but always with an acceptable probability that will depend on two factors: the control parameters and the difference in values that the objective function takes.

Input data that were used:

- Travel distance matrix between each of the generation points and the collection centre, considering vehicle traffic restrictions.

- Travel time matrix between each of the generation points and the collection centre, taking into account vehicle traffic restrictions.

- Vehicle capacity.

- Workday at the collection centre.

- Number of $20 \mathrm{~L}$ containers with waste vegetable oil to collect at each generation points. 
DESIGN OF WASTE VEGETABLE OIL COLLECTION NETWORKS APPLYING VEHICLE ROUTING PROBLEM AND SIMULTANEOUS PICKUP AND DELIVERY

Lisandra Quintana; Yalexa Herrera-Mena; José L. Martínez-Flores; Marcos A. Coronado; Gisela Montero; Patricia Cano-Olivos

- Number of $20 \mathrm{~L}$ empty containers to be delivered at each generation points.

- Load time at the collection centre.

- Unload time at the generation points.

- Generation points time window.

- Collection centre time window.

\section{Results and discussion}

The solution is shown in Figure 2, taking into account the geographical location of the generation points and the collection centre.

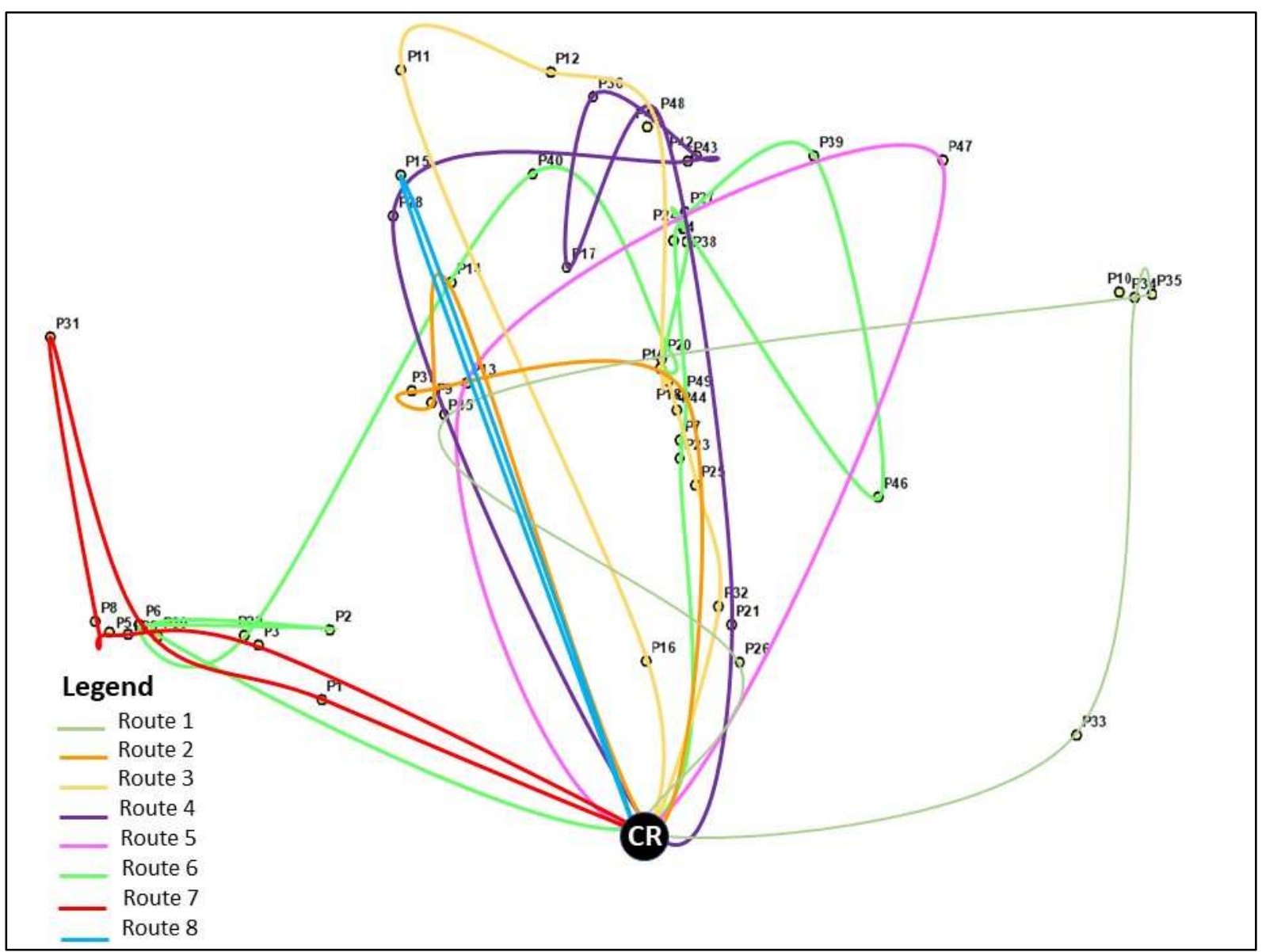

Figure 2 Collection networks for new customers

Table 2 shows a summary of the long times of each route, the distance travelled to execute them, as well as the load transported and advantage of the vehicle's capacity on each trip.

Table 2 Routes of collection of waste vegetable oil

\begin{tabular}{|c|c|c|c|c|c|}
\hline \multicolumn{2}{|c|}{ Routes with 6 $t$ van } & $\begin{array}{c}\text { Time } \\
(\mathrm{min})\end{array}$ & $\begin{array}{c}\text { Distance } \\
(\mathrm{km})\end{array}$ & $\begin{array}{c}\text { Load }(20 \mathrm{~L} \\
\text { containers })\end{array}$ & Capacity use \\
\hline 1 & CR-P33-P34-P35-P45-P26-CR & $\mathbf{1 9 9 . 5 1}$ & $\mathbf{2 0 . 8 0}$ & $\mathbf{6 1}$ & $\mathbf{9 0 \%}$ \\
\hline 2 & CR-P14-P9-P37-P49-CR & $\mathbf{1 4 0 . 3 5}$ & $\mathbf{1 4 . 1 5}$ & $\mathbf{2 3}$ & $\mathbf{3 4 \%}$ \\
\hline 3 & $\begin{array}{c}\text { CR-P32-P25-P18-P10-P41-P12- } \\
\text { P11-P16-CR }\end{array}$ & $\mathbf{1 7 6 . 6 8}$ & $\mathbf{1 9 . 4 0}$ & $\mathbf{5 7}$ & $\mathbf{8 4 \%}$ \\
\hline 4 & $\begin{array}{c}\text { CR-P21-P48-P17-P36-P43-P42- } \\
\text { P28-CR }\end{array}$ & $\mathbf{1 8 9 . 5 1}$ & $\mathbf{2 2 . 4 2}$ & $\mathbf{4 1}$ & $\mathbf{6 0 \%}$ \\
\hline 5 & CR-P13-P47-CR & $\mathbf{1 4 8 . 2 2}$ & $\mathbf{1 6 . 9 0}$ & $\mathbf{5 6}$ & $\mathbf{8 2 \%}$ \\
\hline \multicolumn{2}{r|}{ TOTAL } & $\mathbf{8 5 4 . 2 7}$ & $\mathbf{9 3 . 6 7}$ & $\mathbf{2 3 8}$ & \\
\hline
\end{tabular}


DESIGN OF WASTE VEGETABLE OIL COLLECTION NETWORKS APPLYING VEHICLE ROUTING PROBLEM AND SIMULTANEOUS PICKUP AND DELIVERY

Lisandra Quintana; Yalexa Herrera-Mena; José L. Martínez-Flores; Marcos A. Coronado; Gisela Montero; Patricia Cano-Olivos

\begin{tabular}{|c|c|c|c|c|c|}
\hline \multicolumn{2}{|c|}{ Routes with 8 t van } & $\begin{array}{c}\text { Time } \\
(\mathrm{min})\end{array}$ & $\begin{array}{c}\text { Distance } \\
(\mathrm{km})\end{array}$ & $\begin{array}{c}\text { Load }(20 \mathrm{~L} \\
\text { containers })\end{array}$ & Capacity use \\
\hline 6 & $\begin{array}{c}\text { CR-P30-P2-P29-P22-P40-P20- } \\
\text { P19-P38-P24-P46-P39-P27-P4- } \\
\text { P44-P7-P23-CR }\end{array}$ & $\mathbf{4 6 9 . 4 7}$ & $\mathbf{2 6 . 4 2}$ & $\mathbf{1 6 9}$ & \\
\hline 7 & CR-P1-P6-P31-P8-P5-P3-CR & $\mathbf{3 7 8 . 2 9}$ & $\mathbf{1 8 . 4 1}$ & $\mathbf{3 7}$ & $\mathbf{5 0 \%}$ \\
\hline 8 & CR-P15-CR & $\mathbf{5 3 8 . 6 1}$ & $\mathbf{1 4 . 6 0}$ & $\mathbf{2 5 6}$ & $\mathbf{1 1 \%}$ \\
\hline \multicolumn{2}{r|}{ TOTAL } & $\mathbf{1 , 3 8 6 . 3 7}$ & $\mathbf{5 9 . 4 3}$ & $\mathbf{4 6 2}$ & \\
\hline
\end{tabular}

It will not be possible to make all the visits on a working day, because the time it takes to make all the visits exceeds the workday established of the collection centre. Therefore, it should be considered when scheduling the delivery and collection process.

The allocation of the load in the vehicles is acceptable, however, the capacity use of the $8 t$ Van is only 46 percent, while the utilization of the $6 t$ Van capacity is 70 percent. Finally, the use of the dynamic capacity of the vehicle is low, which could impact badly in the efficiency of the distribution process.

\section{Conclusions}

It is appropriate to carry out a strategy to prevent pollution that allows the creation of an environmental training supported by strategic, tactical and operational decisions, that are the bases for the design of a recovery logistic system, permitting the evaluation of the waste generated in the current supply chain.

The collection is a fundamental process of the recovery logistic system, which consist of collecting the waste and deliver the container for its later collection, this task is only possible by connecting all the waste generators with the collection centre throughout the design of a collection and distribution network. Therefore, the waste vegetable oil collection is a vehicle routing problem with simultaneous deliveries and collection, considering time restrictions and a heterogeneous vehicle fleet.

The VRDSPTW is a complex problem, due to the process's restrictions and the number of nudes that form part of the network, therefore, it was necessary for the current problem the utilization of simulated recursive metaheuristic, which made possible to reach a feasible solution in less time, obtaining $49 \mathrm{WVO}$ generation points. Finally, the analysis of the previous results obtained by the free VPRPD software, showed 8 routes for a vehicle capacity utilization of 70 percent in the $6 t$ vehicle and 46 percent in the $8 t$ vehicle, highlighting lower exploitation of the dynamic capacity.

The results presented in this investigation are the beginning of a project to design a logistic system for the recovery of waste vegetable oil. Therefore, in future studies the following elements should be considered:

- Perform a comparison with future results by using other metaheuristics to select the most feasible solution.
- Analysis of the collection centre's capacity to deal with an increase in the volume of residual to be collected.

- Include transport indicators as restrictive elements of the model.

- Combine the collection of waste vegetable oil generated by the restaurant and the domestic sector.

- Make an assignment of the clients that would be attended by the collection centre itself and by the contracted company, seeking better use of vehicular capacity and resource optimization.

\section{Acknowledgement}

The present research is a product from the support and collaboration of several organizations, as the National Council of Science and Technology (CONACYT, for its acronym in Spanish), Universidad Autónoma de Baja California (UABC) and the Universidad Popular Autónoma del Estado de Puebla (UPAEP). Also, to recognize the work of Lisandra Quintana as a student of the Master and PhD Program in Sciences and Engineering (MYDCI) in UABC, with CVU- 930829 and Yalexa Herrera as students of the Logistics $\mathrm{PhD}$ Program in UPAEP, with CVU- 1010372. Both with a scholarship program by CONACYT.

\section{References}

[1] Secretaria de Medio Ambiente y Recursos Naturales (SEMARNAT), Reporto on the situation of the environment in Mexico, Ciudad de México, pp. 431469, 2016. (Original in Spanish)

[2] GUI, M., LEE, K., BHATIA, S.: Feasibility of edible oil vs. non-edible oil vs. waste edible oil as biodiesel feedstock, Energy, Vol. 33, No. 11, pp. 1646-1653, 2008. doi:10.1016/j.energy.2008.06.002

[3] GHISELlINI, P., CIALANI, C., ULGIATI, S.: A review on circular economy: the expected transition to a balanced interplay of environmental and economic systems, Journal of Cleaner Production, Vol. 114, No. February, pp. 11-32, 2016. doi:10.1016/j.jclepro.2015.09.007

[4] MYERS, G.: Soap and detergents, in Inedible Meat by - Products, $1^{\text {st }}$ ed., A. Pearson and T. Dutson, Ed. Inglaterra: Elsevier Science Publishers LTD, 1992.

[5] MONTERO, G., TOYTCHEVA, M.S., CORONADO, M., GARCÍA, C., CEREZO, J., TOSCANO, L., 
DESIGN OF WASTE VEGETABLE OIL COLLECTION NETWORKS APPLYING VEHICLE ROUTING PROBLEM AND SIMULTANEOUS PICKUP AND DELIVERY

Lisandra Quintana; Yalexa Herrera-Mena; José L. Martínez-Flores; Marcos A. Coronado; Gisela Montero; Patricia Cano-Olivos

VÁZQUEZ, A.M., LEÓN, J.A.: An Overview of Biodiesel Production in Mexico, in Biofuels Status and Perspective, $1^{\text {st }}$ ed., K. Biernat, Ed. Londres: Intechopen, 2015.

[6] FLÓREZ CALDERÓN, L., TORO OCAMPO, E., GRANADA ECHEVERRY, M.: Diseño de redes de logística inversa: Una revisión del estado del arte y aplicación práctica, Ciencia e Ingeniería Neogranadina, Vol. 22, No. 2, pp. 153-177, 2012.

[8] Secretaria de Medio Ambiente y Recursos Naturales (SEMARNAT), Diagnostico Básico para la Gestión Integral de los Residuos, Lucart Estudio S.A. de C.V, Ciudad de México, 2020.

[9] CHARONIS, G.K.: Sustainability - Missing Points in the Development Dialogue, in Degrowth, steady state economics and the circular economy: three distinct yet increasingly converging alternative discourses to economic growth for achieving environmental sustainability and social equity, World Economics Association, 2012.

[10] CERDÁ, E., KHALILOVA, A.: Economía circular, Economía Industrial, Vol. 401, pp. 11-20, 2016. (Original in Spanish)

[11] Ellen MacArthur Foundation, Towards a Circular Economy: Business rationale for an accelerated transition, Ellen MacArthur Foundation, United Kingdom, 2015.

[12] WINKLER, H.: Closed-loop production systems-A sustainable supply chain approach, CIRP Journal of Manufacturing Science and Technology, Vol. 4, No. 3, pp. 243-246, 2011. doi:10.1016/j.cirpj.2011.05.001

[13] GHISELlinI, P., CIALANI, C., UlGiATI, S.: A review on circular economy: the expected transition to a balanced interplay of environmental and economic systems, Journal of Cleaner Production, Vol. 114, No. February, pp. 11-32, 2016. doi:10.1016/j.jclepro.2015.09.007

[14] Camara de Diputados, Diputados.gob.mx, 2020. [Online] Available: http://www.diputados.gob.mx [Accessed: 20- Jun- 2020], 2020. (Original in Spanish)

[15] FERNÁNDEZ ARIAS, A., ALLENDE ALONSO, S.: Estrategia GRASP para el Problema de Enrutamiento de Vehículos con Recogida y Entrega Simultánea, Revista Investigación Operacional, Vol.
38, No. 4, pp. 424-435, 2017. (Original in Spanish)

[16] GONZÁLEZ-LA ROTTA, E., BECERRAFERNÁNDEZ, M.: Cross-docking with vehicle routing problem. A state of art review, Plataformas de intercambio con ruteo de vehículos. Una revisión del estado del arte, DYNA, Vol. 84, No. 200, pp. 271-280, 2017. doi:10.14483/23448393.3832 (Original in Spanish)

[17] BERBEGLIA, G., CORDEAU, J., LAPORTE, G.: Dynamic pickup and delivery problems, European Journal of Operational Research, Vol. 202, No. 1, pp. 8-15, 2010. doi:10.1016/j.ejor.2009.04.024

[18] Berbeglia, G., Cordeau, J., Gribkovskaia, I., Laporte, G.: Rejoinder on: Static pickup and delivery problems: a classification scheme and survey, TOP, Vol. 15, No. 1, pp. 45-47, 2007. doi:10.1007/s11750007-0009-0

[19] MIN, H.: The multiple vehicle routing problem with simultaneous delivery and pick-up points, Transportation Research Part A: General, Vol. 23, No. 5, pp. 377-386, 1989. doi:10.1016/01912607(89)90085-X

[20] BALLESTEROS SILVA, P., ESCOBAR ZULUAGA, A.: Review of state of the art vehicle routing problem with pickup and delivery (VRPPD), Ingeniería y Desarrollo, Vol. 34, No. 2, pp. 463-482, 2016. doi:10.14482/inde.33.2.6368

[21] FERNANDEZ ARIAS, A.: Modelos y Métodos para el Problema de Enrutamiento de Vehículos con Recogida y Entrega Simultanea, Universidad de La Habana, La Habana, 2013. (Original in Spanish)

[22] DELL'AMICO, M., RIGHINI, G., SALANI, M.: A Branch-and-Price Approach to the Vehicle Routing Problem with Simultaneous Distribution and Collection, Transportation Science, Vol. 40, No. 2, pp. 235-247, 2006. doi:10.2307/25769299

[23] HERNAN RESTREPO, J., MEDINA, P.V., CRUZ, T. E.: Un problema logístico de programación de vehículos con ventanas de tiempo (VRPTW), Scientia et Technica, Vol. 39, No. September, pp. 229-234, 2008. doi:10.22517/23447214.3195 (Original in Spanish)

\section{Review process}

Single-blind peer review process. 